\title{
Application of Mind Map in Principles of Computer Organization
}

\author{
Lei Wei ${ }^{1, a}$, Qiuyun Zhao ${ }^{1, b}$ \\ ${ }^{1}$ School of Computer, Chengdu University of Information Technology, Chengdu, China \\ aweile@cuit.edu.cn, bzqyuen@cuit.edu.cn \\ * Lei Wei
}

Keywords: Principles of Computer Organization; Mind Map; Knowledge visualization; Question guidance.

\begin{abstract}
According to characteristics of Principles of Computer Organization which contents is complicated and knowledge is difficult to remember and understand, as well as the problem that the current teaching mode can not mobilize students' active learning awareness and lacks creative thinking training, we propose a teaching method of Principles of Computer Organization based on Mind Map. The application of Mind Map is elaborated from aspects of teachers' preparation, teaching and students' learning. Examples are given to illustrate how to combine Mind Map and question guidance in order to improve students' enthusiasm and innovative thinking in class. Application of Mind Map has stimulated students' interest in learning, improved the quality of the course teaching, and cultivated the students' holistic and divergent thinking.
\end{abstract}

\section{Introduction}

Principles of Computer Organization is a major compulsory course in computer science. It plays an important role in the course system of hardware category [1]. This course takes single machine system as the research object, and focuses on the logic composition and working mechanism of the computer hardware system. Through the study of this course, students should understand principles of logic devices and components commonly used in computers, learn the basic principle of the simple and complete single CPU computer, build the whole concept of the computer system, master computer expertise to solve complex engineering problems, and develop students' ability to design and complete experiments and the ability to acquire knowledge.

The computer major in domestic universities attaches great importance to the achievement of the teaching objectives for Principles of Computer Organization, and reforms of the curriculum teaching are carried out in many aspects [2-4] to improve the teaching quality. These reforms have made some achievements. Due to the complexity of this course, the content is more theoretical, need to be remembered and understand more parts then others. It is difficult for students to master the relevant knowledge. Especially under the Engineering Education background, the course needs to carry the training of students' abilities, but it is obviously that the traditional teaching mode and teaching methods cannot fully undertake this task.

Mind Map is a visual thinking method [5] and a thinking tool, which emphasizes using the brain's own language to conceive and express, so that the brain is in a state of positive thinking and continuous creation. Mind Map has also been used in the field of Higher Education widely [6-8]. A large number of existing research and practice show that Mind Map has good effect in deepening students' understanding of professional knowledge, training students' ability to use, induce and analyze the problems comprehensively, promoting the development of students' thinking. It is especially excellent for the development of innovative thinking. Therefore, we use the Mind Map method, focus on the current problems and combine with the actual needs of teaching. The introduction of Mind Map in the course teaching achieved good achievements. 


\section{Application of Mind Map in principles of computer organization}

\subsection{Application of Mind Map in teachers' preparation}

At present, Principles of Computer Organization takes the computer of John von Neumann system as the object of instruction, and focuses on the composition and working principle of computer. The content is divided into the CPU subsystem (including the arithmetic unit and controller), storage subsystem, input-output system and input output device. The overall structure is relatively clear. Because each part involves much knowledge which are complicated, and there are the cross relation in the existing teaching material with the content arrangement, it's difficult for teachers especially the new ones to sort out all the content of curriculum knowledge system. Teachers are easy to focus on points, difficult to explain the knowledge in the way of organic association when teaching.

To introduce Mind Map into teacher's preparation, teachers could use knowledge visualization tools, combined with teaching materials, teaching outline, teaching plan and so on. Above all, draw the first level mind map on the whole of the course, so as to grasp the content of the teaching from the macro. Then draw the first level mind map by chapter, and identify the key, difficulty and teaching forms in the figure, which presents the knowledge of the larger granularity of the course, and helps to form a knowledge system. At last, draw the first level mind map by knowledge points, and mark the specific teaching method in the map, so that the knowledge thread of the whole course is very clear, as well as the connection between knowledge points. In addition, in the course ware, teachers can also appropriately add elements of Mind Map, which is conducive to the knowledge navigation for students. The first level mind map by chapter of the course is shown in Figure 1.

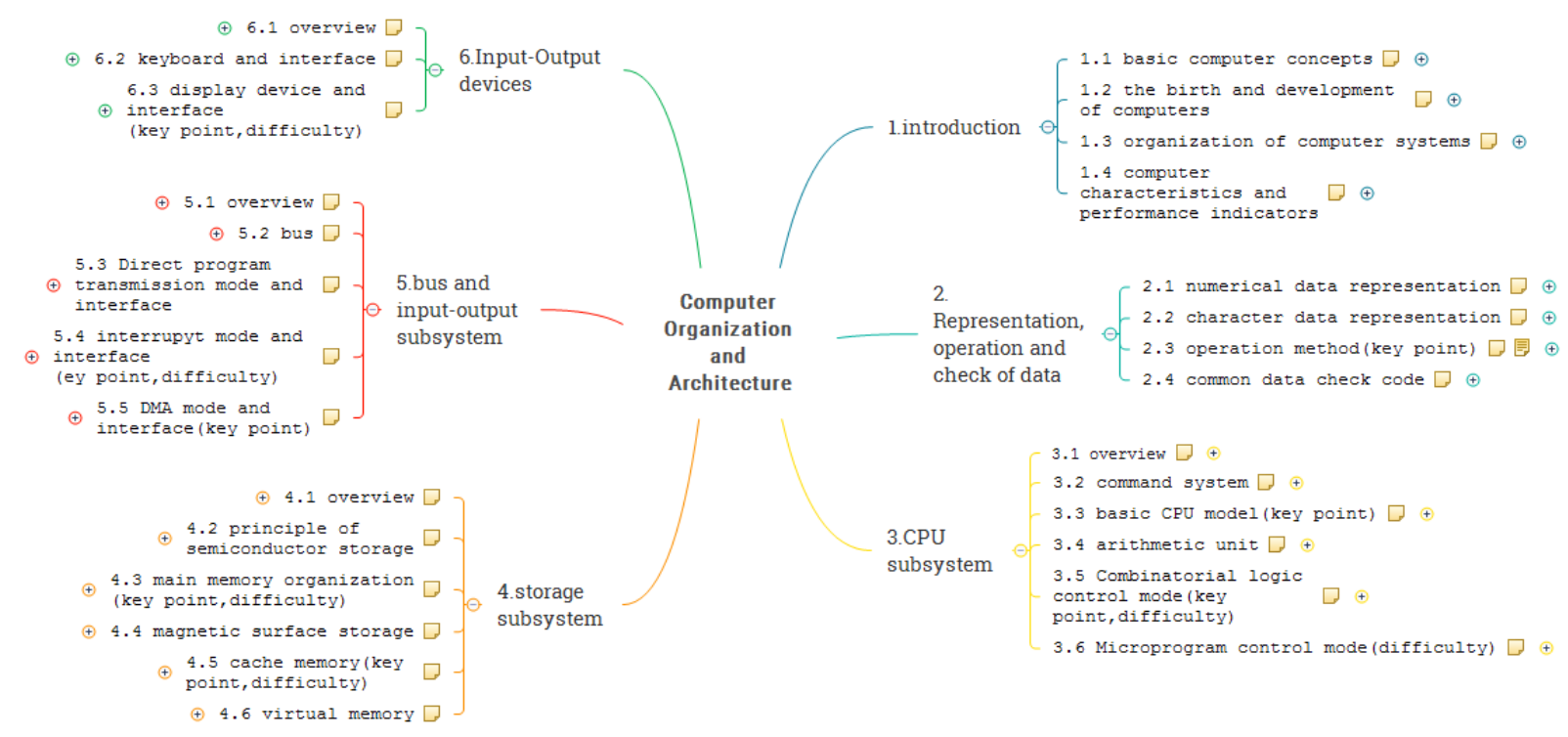

Fig.1: Chapter level mind map of Principles of Computer Organization

\subsection{Application of Mind Map in classroom teaching}

The traditional teaching method of 'cramming' only focus on the inculcation of knowledge in teaching activities, with teachers as the center. Students can not fully participate in teaching activities. The traditional teaching more emphasis on 'teaching', while ignoring the teaching is learning. The student participation is not high and lack of the guidance for students which leads students to active thinking, ask questions. It is difficult to effectively stimulate the enthusiasm of students, to cultivate students' ability to analyze and solve problems, and innovative thinking. The introduction of Mind Map in Principles of Computer Organization can solve these problems better. The specific methods are as follows:

(i) Before teaching, teachers would find out the main points and difficulties of the lecture, set up some problems beforehand, and draw a preliminary mind map; In class, teachers could start teaching 
with the initial mind map, guides students to think deeply for the important knowledge points, so as to deeply understand the relevant principles and improve Mind Map with the students. At the end, students are given a summary of the content by using the improved mind map, so that students could understand and master this knowledge as a whole.

(ii) In the knowledge explanation, attention should be paid to the combination of the mind map and the problem guidance, which is to say when explaining principle, first introduce questions and use a mind map to describe these problems. Then guide students to carry out thinking and discussion on these issues and brainstorming. Finally, the solution of the problem is integrated with the relevant knowledge, and the whole process is presented with the mind map. For example, when explaining the information transmission control mode, make a mind map to describe the three problems to be solved: (1)After the CPU starts the peripherals, the peripherals would be prepared for a while, so whether the CPU is waiting or executing the program in parallel of the process of setting up or doing a specific operation? (2) If CPU executes the program in parallel, then how do you notify CPU when the peripheral work is completed? (3)Does CPU achieves $\mathrm{I} / \mathrm{O}$ transmission through the program or hardware? The following are the three questions which revolve around the direct program delivery, interrupt mode, and DMA mode. Questions actively guide students to think, and finally to explain how the three ways solve these problems. And a mind map could be drawn to explain solutions. The mind map of the information transmission control method based on problem guidance is shown in figure 2 .

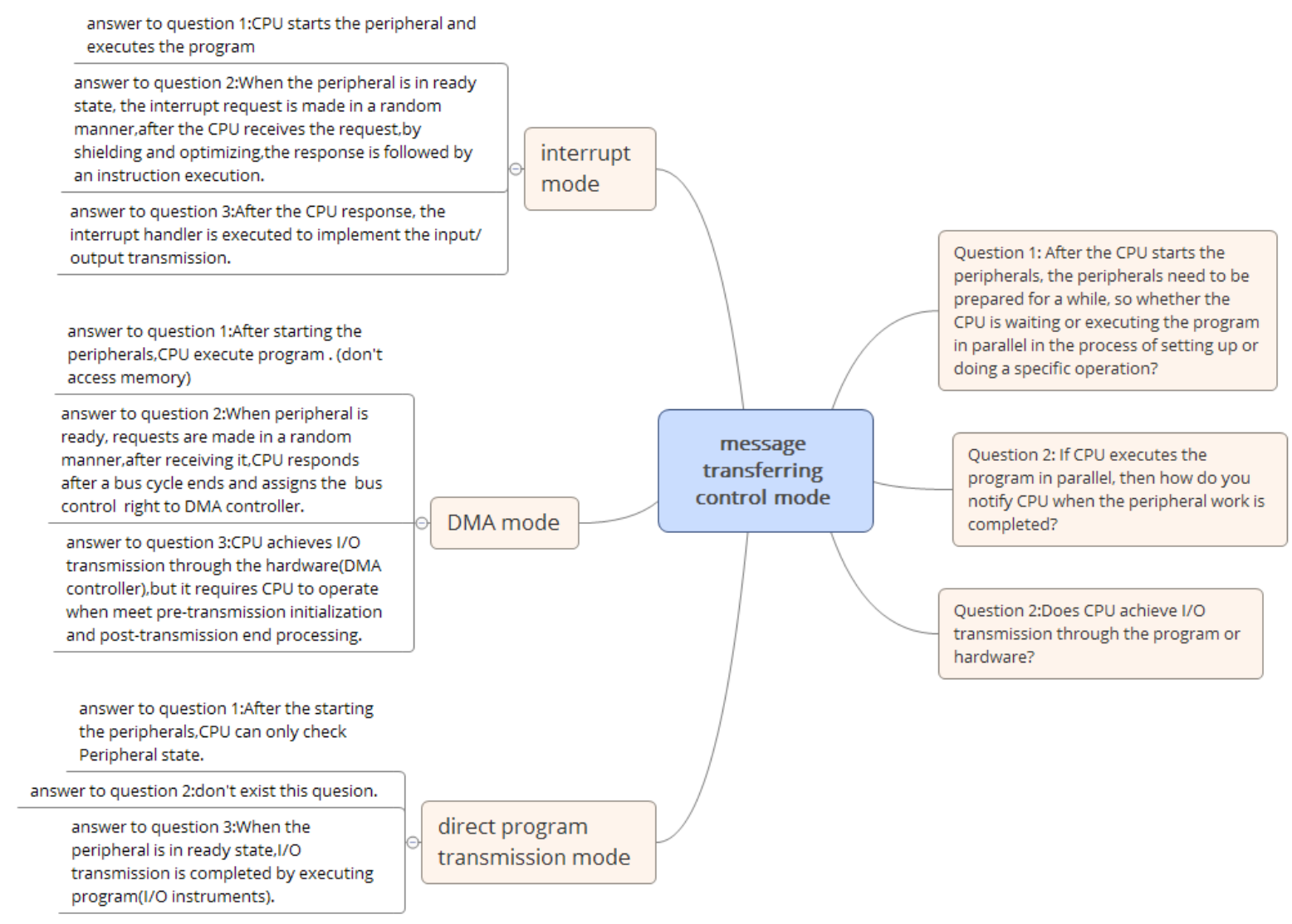

Fig.2: Mind map based on problem guidance

\subsection{Application of Mind Map in the learning process of students}

Mind Map is applied to preview, class and review of students' learning process. It can play a better role, and the effect is very obviously. In the preview stage, students could use Mind Map, quickly create knowledge framework, understand the relationship between knowledge, identify difficulties of knowledge and pinpoint problems. In the classroom learning stage, students could improve Mind Map according to the content explained by the teacher, solve the problems encountered during the 
preparation, and complete the class notes. At the same time, by comparing with the mind map drawn by teachers, students would clearly find out the omission in the preview. In the review, the use of early thinking according to chapters and themes from the review guide map would help students build a complete knowledge network, clarify the relationship between knowledge points, identify the key points and difficulties, and deepen the memory and understanding of knowledge.

\section{Conclusion}

Mind Map reproduces the thought process in a visual form, and presents the complex knowledge system at a glance through the relationships among themes, lines and drawings. The application effect shows that the application of Mind Map in Principles of Computer Organization can effectively help students to build a good cognitive structure, construct a complete curriculum knowledge system, clarify the relationship between knowledge points, deepen the memory and understanding of knowledge, but also help stimulate students' learning interest, and cultivate students' innovative thinking ability. Next, we hope to combine Mind Map with the idea of the engineering education, and try to build a new mode of Mind Map based on CDIO.

\section{Acknowledgement}

This paper is supported by Principles of Computer Organization high-quality curriculum construction project of Chengdu University of Information Technology, and the construction stage research achievements of the fifth batch of characteristic specialties of the Ministry of Education Computer Science and Technology (TS2488).

\section{References}

[1] Q. Y. Zhao, J. He, and L Wei, Discussion on the teaching mode of Computer Organization and Architecture, Computer Knowledge and Technology, vol. 3, pp. 693-694, 2008.

[2] X. H. Peng, The application of PBL mode in the teaching reform of Computer Organization and Architecture, Modern Computer, vol. 21, pp. 25-28, 2012.

[3] J. H. Wang, Y. Li, and Y. L. Huang, Study on application and practice of flipped classroom in Computer Organization and Architecture, Electronic Test, vol. 7, pp. 63-64, 2016.

[4] H. M. Luo, Z. K. Yan, and L. Wu. Research on the teaching reform of Computer Organization and Architecture based on Constructivism. China Electric Power Education, vol. 22, pp. 73-74, 2012.

[5] Z. M. Liu, Z. X. Du, and S. W. Yu, Teaching practice of mind map method, Science of Surveying and Mapping, vol. 9, pp. 186-190, 2016.

[6] J. Zhang. Discussion on the teaching application of Computer Network based on mind map. China Computer \& Communication, vol. 8, pp. 242-244, 2017.

[7] Q. Y. Kang, Z. X. Han, and J. F. Wang. Research on the teaching method of "Basis of Communication Network" based on mind map. Industry and Information Technology Education, vol. 4, pp. 42-47, 2017.

[8] W. W. Ding. The application of mind map in JAVA teaching. Journal of Huaibei Normal University(Natural Sciences), vol. 2, pp. 87-91, 2017. 